\title{
Differential thermometer for studying cerebral asymmetry
}

\author{
JAMES M. DABBS, JR. \\ Georgia State University, Atlanta, Georgia 30303 \\ ALBERT L. RUFF \\ SAS Systems, Inc., Norcross, Georgia 30071 \\ and \\ CHARLES H. HOPPER \\ Georgia State University, Atlanta, Georgia 30303
}

\begin{abstract}
A device for measuring differences in temperature between the two sides of the head is described. The unit can be used for studying individual differences in cerebral asymmetry.
\end{abstract}

Temperature differences between the two sides of the head may provide information on the functioning of the brain. Temperature over the ophthalmic arteries can indicate occlusion of the carotid arteries (Conrad, Toole, \& Janeway, 1969), and temperature differences between left and right ophthalmic arteries has been related to differences in verbal and spatial ability (Dabbs \& Choo, 1980). The brain generates about $20 \%$ of the total body heat in an adult and $70 \%$ in an infant (Cross \& Stratton, 1974); temperature at the skin is affected by this internal source of heat (see Dabbs, 1980). Temperature differences between the two sides of the head could be related to differences in morphology or activity between the left and right sides of the brain.

\section{GENERAL DESCRIPTION}

The device described here measures temperature differences between two probes to the nearest $.01^{\circ} \mathrm{C}$. It is small, battery powered, and has both digital and analog output. Its probes are attached to flexible leads, which can be taped to the temples to measure differences between the two sides of the head.

\section{TEMPERATURE PROBES}

The probes utilize the AD590 (Analog Devices, P.O. Box 280, Norwood, Maine 02062), an integrated circuit that emits current proportional to absolute temperature. The AD590 has advantages over both thermistors and thermocouples for measuring small temperature differences. Thermistors require more

The work reported here was supported by a grant from the Spencer Foundation. We thank Harry Hopkins for the use of his differential microcalorimeter. Request reprints from James $M$. Dabbs, Jr., Department of Psychology, Georgia State University, Atlanta, Georgia 30303. support circuitry and are more difficult to calibrate than the AD590, and thermocouples produce voltages that are small and difficult to measure accurately.

We used the AD590 version of the AD590LF; the device is $1.4 \times 2.7 \times 5.8 \mathrm{~mm}$ in size, with leads protruding from one end. The leads are trimmed to about $5 \mathrm{~mm}$ and soldered to a 5 -ft twisted pair of small and extremely flexible cables (30 AWG stranded wire, NUF30-4046, Cooner Sales Corporation, 9186 Independence, Chatsworth, California 91311). The solder connection is bent back parallel to the top of the AD590, and a drop of epoxy insulates the connection and secures it to the top of the AD590. The assembly is cemented with cyanoacrylate adhesive (Superglue) to a .5 -in. (12.5-mm) disk of .01 -in. (.25-mm) copper stock. The copper disk dampens rapid changes in termpeature and averages temperature over an area larger than the AD590 itself. Different size disks can be used, depending upon the investigator's needs, or the probes can be embedded in ear plugs to measure temperature near the tympanic membranes. The probes are attached to the thermometer. The circuit is shown in Figure 1; Table 1 provides a list of components.

\section{CIRCUIT DESCRIPTION}

The thermometer circuit measures the difference in current flowing through two temperature probes (AD590LFs) that nominally have equal currents flowing at equal temperatures. This differential current is applied to the inverting input of an operational amplifier (LM308A) with a feedback loop chosen to produce an analog voltage of $100 \mathrm{mV}$ per ${ }^{\circ} \mathrm{C}$. Capacitive filtering in the feedback loop and at the output reduces transients due to radio-frequency or electromagnetic interference.

The analog voltage is then passed to a single-chip dualslope analog-to-digital (A-to-D) converter (MC14433P). 


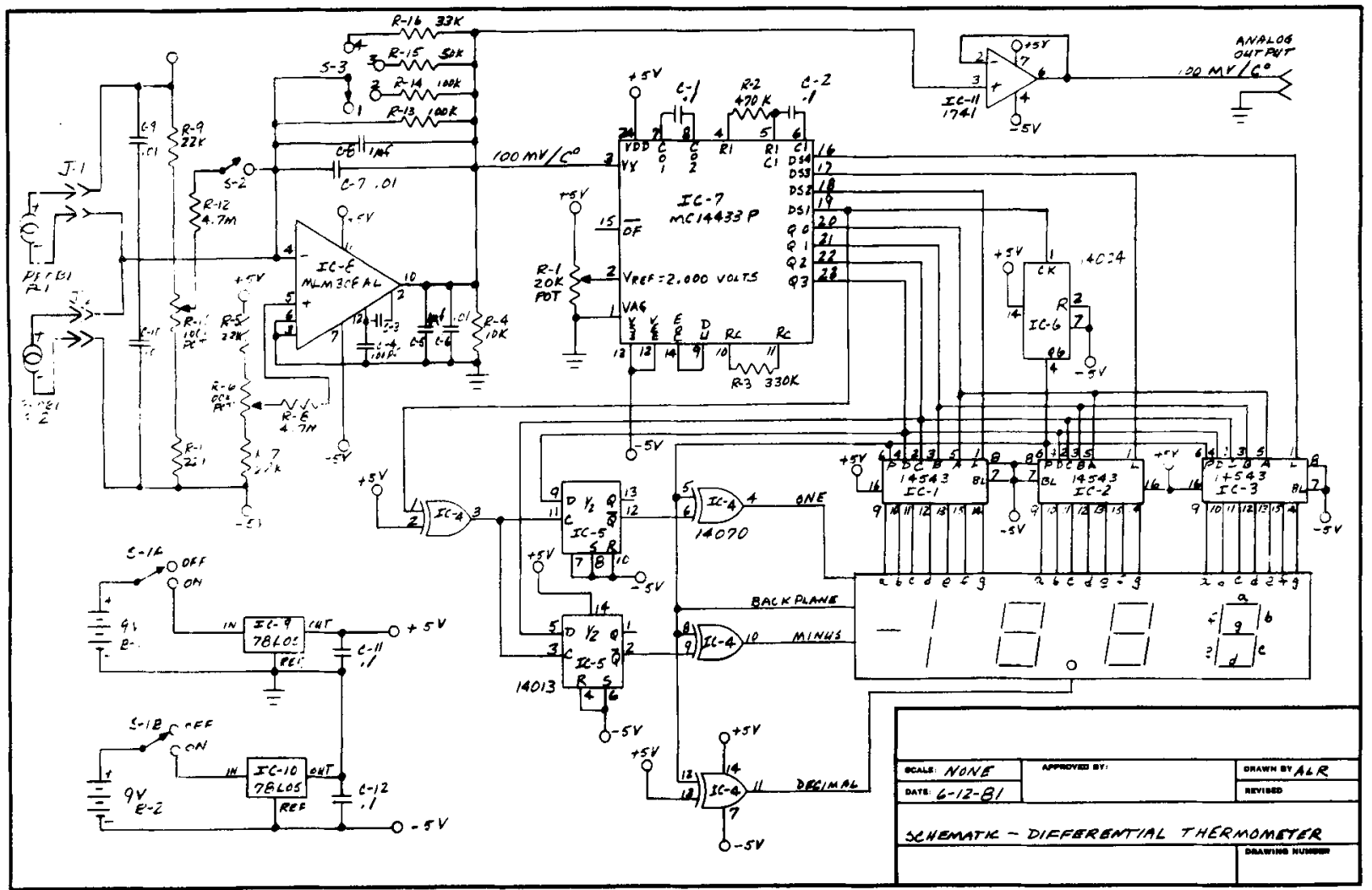

Figure 1. Circuit diagram for differential thermometer.

Table 1

Parts List

\begin{tabular}{|c|c|c|c|}
\hline Item & Description & Part Number & Manufacturer \\
\hline Display & Liquid crystal display & $3918-315$ & Hamlin, Inc. \\
\hline IC- $1,2,3$ & Display driver & $\mathrm{MC} 14543 \mathrm{BCP}$ & Motorola Semiconductor \\
\hline IC -4 & Exclusive OR gate & $\mathrm{MC14070BCP}$ & Motorola Semiconductor \\
\hline IC-5 & Flip-flop & MC14013BCP & Motorola Semiconductor \\
\hline IC -6 & Counter & $\mathrm{MC1} 4024 \mathrm{BCP}$ & Motorola Semiconductor \\
\hline IC-7 & A to $\mathrm{D}$ converter & $\mathrm{MC14433BCP}$ & Motorola Semiconductor \\
\hline IC -8 & Op amp & MLM 308AL & Motorola Semiconductor \\
\hline IC-9,10 & Voltage regulator & MC78L05CP & Motorola Semiconductor \\
\hline IC -11 & Op amp & $\mathrm{MC} 1741 \mathrm{CP}$ & Motorola Semiconductor \\
\hline R-1 & $20 \mathrm{~K}$ potentiometer & $3006 \mathrm{P}-1-203$ & Bourns, Inc. \\
\hline R-2 & $470 \mathrm{~K}, 1 / 4 \mathrm{~W}, 5 \%$ & & Bourns, Inc. \\
\hline R-3 & $330 \mathrm{~K}, 1 / 4 \mathrm{~W}, 5 \%$ & & Bourns, Inc. \\
\hline $\mathrm{R}-4$ & $10 \mathrm{~K}, 1 / 4 \mathrm{~W}, 5 \%$ & & Bourns, Inc. \\
\hline $\mathrm{R}-5,7,9,11$ & $22 \mathrm{~K}, 1 / 4 \mathrm{~W}, 5 \%$ & & Bourns, Inc. \\
\hline R-6,10 & $100 \mathrm{~K}$ potentiometer & $271-1722$ & Radio Shack \\
\hline $\mathrm{R}-8,12$ & $4.7 \mathrm{M}, 1 / 4 \mathrm{~W}, 10 \%$ & & Radio Shack \\
\hline $\mathrm{R}-13$ & $100 \mathrm{~K}, 1 / 4 \mathrm{~W}, 1 \%$ & & Radio Shack \\
\hline R-14 & $100 \mathrm{~K}, 1 / 4 \mathrm{~W}, 1 \%$ & & Radio Shack' \\
\hline $\mathrm{R}-15$ & $50 \mathrm{~K}, 1 / 4 \mathrm{~W}, 1 \%$ & & Radio Shack \\
\hline$R-16$ & $33 \mathrm{~K}, 1 / 4 \mathrm{~W}, 1 \%$ & & Radio Shack \\
\hline C- $1,2,11,12$ & .1 micro $F$ mylar & & Radio Shack \\
\hline C- 3,4 & 100 picaF disk & & Radio Shack \\
\hline C- $-5,8$ & 1 microF nonpolarized & & Radio Shack \\
\hline$C-6,7,9,10$ & .01 microF disk & & Radio Shack \\
\hline $\mathrm{J}=1,2,3$ & Subminiature jack & $274-292$ & Radio Shack \\
\hline S-1 & Double pole, double throw & $275-663$ & Radio Shack \\
\hline S-2 & Single pole, single throw & $275-324$ & Radio Shack \\
\hline S-3 & 4-position rotary & $275-1386$ & Radio Shack \\
\hline P-1,2 & Probes & $\mathrm{AD}-590 \mathrm{LF}$ & Analog Devices \\
\hline \multirow{2}{*}{ B-1,2 } & $9-V$ transistor battery & $23-464$ & Radio Shack \\
\hline & Battery clips & $270-325$ & Radio Shack \\
\hline
\end{tabular}


The digitized information from the A-to-D converter is decoded by three seven-segment decoders (MC14543B) to provide three full digits of displayed information on a liquid crystal display (Hamlin 3918-315). The one, minus sign, and decimal point are decoded and driven by a flip-flop (14013B) and four exclusive-OR gates (140708B). A binary counter (14024B) is used to divide the internal oscillator in the A-to-D converter down to a frequency (approximately $50 \mathrm{~Hz}$ ) suitable for driving the backplane of the liquid crystal display. The positive and negative $5 . \mathrm{V}$ supplies are regulated separately (78L05s). The analog voltage at the output of the LM308A is also buffered by another operational amplifier (741) and passed to an external analog output connector for use with a conventional chart recorder. (Specification sheets are available on the integrated circuits from Motorola Semiconductor Products, 3501 Ed Bluestein Boulevard, Austin, Texas 78712. The liquid crystal display specifications can be obtained from Hamlin, Lake Mills, Wisconsin 53551. A printed circuit board layout is available from the authors.)

The only internal circuit calibration consists of setting the $2.000-\mathrm{V}$ reference for the A-to-D converter. There are two operating adjustments. The first is a circuit zero to compensate for initial selection error among circuit components and for changes in power supply voltage. The second is a probe zero to compensate for initial differences between the probes; it is set to zero after the probes have been placed in contact with one another, wrapped in cotton, and held in the hand until body temperature is reached. The two operating adjustments are stable and can be performed well in advance of a testing session. Switches S1 and S2 are used to disconnect the temperature probes before making the circuit-zero adjustment and to change the polarity of the probes. Switch S3 changes the value of resistance in the feedback loop of the LM308A so that two or three or four probes can be used in parallel at each probe input to obtain average readings over several sites.

The thermometer fits into a $4 \times 8 \times 2$ in. $(10 \times 20 \times$ $5 \mathrm{~cm}$ ) case and weighs less than $.5 \mathrm{~kg}$. Leads to the temperature probes can be of any length, but they should be color coded to avoid confusion. Power is supplied by two $9 . \mathrm{V}$ cells or two 8.4-V NiCad rechargeable cells. Batteries will last for several hours of operations. After the device is turned on, 2 to $3 \mathrm{~min}$ of circuit warm-up time are needed for accurate temperature readings. In noisy RF environments (e.g., near radiation equipment or outdoors in urban areas) there are sometimes random fluctuations or a few hundredths of a degree in the temperature readings. These can often be reduced by touching the thermometer case or holding the case in one's hand.

\section{RELIABILITY OF THE THERMOMETER}

Reliability of the thermometer was tested using a differential microcalorimeter. The microcalorimeter has a large aluminum block suspended inside an aluminum cylinder, with cell holders (small slots) in the aluminum block 2 in. $(5 \mathrm{~cm})$ apart. The block is maintained at a constant temperature of $35 \pm .0001^{\circ} \mathrm{C}$, and the temperature differences between the cell holders are in the microdegree range.

Thermometer probes were placed in the cell holders, and temperature readings were monitored 10 times over a 7-day period. On each occasion the thermometer was turned on for 5 min to allow the reading to stabilize and then held by the experimenter and monitored for $5 \mathrm{~min}$. During the resulting $50 \mathrm{~min}$ of testing, the temperature reading was almost always exactly $.00^{\circ} \mathrm{C}$. Readings deviated from $.00^{\circ} \mathrm{C}$ for a total of less than $30 \mathrm{sec}(1 \%)$ of the time, and these deviations did not exceed $.01^{\circ} \mathrm{C}$. Thus, the thermometer appears to be accurate within a hundredth of a degree.

\section{RELIABILITY OF INDIVIDUAL DIFFERENCES}

Reliability of the difference in temperature between left and right temples was tested on 57 introductory psychology students, 26 males and 31 females. Measures were taken as follows: Each subject was seated in a comfortable chair in a small room, where the equipment was explained and any questions were answered. A temperature probe was taped to the indentation of the temple just behind each eye with a 1-in. square of Microfoam surgical tape (Minnesota Mining and Manufacturing Company), which conforms well to the probe and the skin and has some insulating effect. The subject was left alone for $3 \mathrm{~min}$, after which the experimenter returned and recorded the difference between right- and left-side temperature every $15 \mathrm{sec}$ for $3 \mathrm{~min}$. The last four of these measures, taken approximately $5 \mathrm{~min}$ after the probes had been placed, were used to compute a mean right-left difference score for each subject. Each subject returned to the laboratory a day or so later at about the same time of day, and the procedure was repeated. The correlation between right-left difference scores on the 2 days over the 57 subjects was $r=.57$.

The temples were selected as measurement sites because they are easily located, usually hairless, and maximally far apart. The sites are nonetheless somewhat arbitrary, and on 28 subjects we used a second thermometer during the same measurement sessions to record temperature differences between two spots closer together on the forehead. The probes were placed above the midpoint of each eye and about halfway between eyebrow and hairline, where an indentation can be felt along the upper edge of the slope to the eyebrow ridge. Reliability of the right-left temperature difference between these points on the forehead was low $(r=.13)$.

\section{APPLICATIONS}

Lateral differences in temperature are useful if they prove to be related to some other significant variable. 
Dabbs and Choo (1980), using a more cumbersome procedure, related right-left differences in ophthalmic temperature to handedness and to individual differences in verbal and spatial ability. Coyle (1981) found temperature differences between the left and right temple, as measured with the present equipment, related to hypnotic susceptibility. By using this equipment with a portable chart recorder, the investigator can monitor continuously the right-left difference in temperature while subjects perform a variety of everyday tasks. We have not, however, generally been successful in finding systematic changes in the right-left difference over periods of time ranging from $30 \mathrm{~min}$ to $2 \mathrm{~h}$.

The AD590 can be used to measure absolute temperature, but we chose to disregard absolute temperature because it is affected by so many extraneous variablesambient temperature, time of day, physical activity. These variables, which produce error in measurement of a subject's absolute temperature, should affect both sides of the head and thus not contribute error to the measurement of right-left differences.

\section{REFERENCES}

Connad, M. C., Toole, J. F., \& Janeway, R. Thermistor recording of forehead skin temperature as an index of carotid artery disease. Circulation, 1969, 39, 126-130.

CoYLE, R. T. Cerebral temperature, hypnotic responsiveness, and functional brain asymmetry. Unpublished doctoral dissertation, Georgia State University, 1981.

Cross, K. W., \& Stratton, D. Aural temperature in the newborn infant. Lancet, 1974, 2, 1179-1180.

DAвв8, J. M., JR. Left-right differences in cerebral blood flow and cognition. Psychophysiology, 1980, 17, 548-551.

Daв8s, J. M., JR., \& ChOo, G. Left-right carotid blood flow predicts specialized mental ability. Neuropsychologia, 1980, 17, 548-551.

(Received for publication January 22, 1981; revision accepted August 24, 1981.) 